\title{
Моделирование методом Монте-Карло поведения частотно-контрастной характеристики фотоприёмных КРТ-матриц вблизи удвоенной частоты Найквиста
}

\author{
А.В. Вишняков, В.А. Стучинский \\ Институт физики полупроводников им. А.В. Ржанова, Новосибирск, \\ 630090, пр. Академика Лаврентьева, 13 \\ тел:+ 7 (383) 330-10-82, факс:+ 7 (383) 330-10-82, эл. почта: vishn@isp.nsc.ru
}

DOI 10.34077/RCSP2021-134

Частотно-контрастная характеристика (ЧКХ) ИК КРТ-фотоприемных матриц убывает с ростом пространственной частоты засветки и обычно проходит через ноль вблизи удвоенной пространственной частоты Найквиста $2 \mathrm{f}_{\mathrm{N}}$ равной обратному шагу матрицы. Если аппроксимировать фоточувствительность пикселя константой в пределах квадрата со стороной $\mathrm{w}$, меньшей или равной шагу матрицы, и нулем - за пределами этого квадрата, то ЧКХ такой площадки равна $\sin (\pi \mathrm{fw}) / \pi \mathrm{fw}(\mathrm{f}$ пространственная частота) и проходит через первый ноль на частоте $f=1 / \mathrm{w}$, равной или большей $2 \mathrm{f}_{\mathrm{N}}$. Как видно из рисунка, на частоте $2 \mathrm{f}_{\mathrm{N}}$ распределение интенсивности синусоидальной волны засветки и соответствующие ему концентрация и ток фотоносителей обладают симметрией относительно границ пикселя, так что нормальная компонента фототока через границы пикселей зануляется. Поэтому имеют место и могут быть использованы простые соображения баланса фотоносителей. Фотоносители собираются на $p$ - $n$-переход и дают вклад в сигнал с расстояний, не больших приблизительно длины диффузии $\mathrm{L}_{\mathrm{d}}$ от ближайшей точки $p$ - $n$-перехода. Если длина диффузии носителей заряда (Н3) превышает расстояние от края $p$ - $n$-перехода до границы пикселя, то площадь сбора заряда совпадает с пикселем, - и вклады положительной и отрицательной полуволн засветки полностью приходят на $p$ - $n$ переход и гасят друг друга. С уменьшением длины диффузии область сбора заряда уменьшается в размере и приближается к границам $p$ - $n$-перехода; при этом отрицательная часть полуволны сигнала частично теряется (так как она расположена дальше от пикселя, чем положительная часть), - и в результате на пикселе возникает положительный результирующий сигнал, то есть при уменьшении длины $\mathrm{L}_{\mathrm{d}}$ ЧКX матрицы возрастает.

Нами было проведено численное моделирование поведения ЧКХ КРТ матрицы с архитектурой $n$ на- $p$ и размером пикселя $15 \times 15$ мкм вблизи частоты $2 \mathrm{f}_{\mathrm{N}}$. Диффузия фотоносителей из узкого линейного пятна засветки моделировалась методом Монте-Карло как случайное блуждание частиц по кубической сетке. Как показывают результаты моделирования, значение ЧКХ на частоте $2 \mathrm{f}_{\mathrm{N}}$ растет с уменьшением площади сбора, то есть с уменьшением длины диффузии НЗ и размеров $p$ - $n$-перехода. ЧКХ на частоте $2 \mathrm{f}_{\mathrm{N}}$ изменяется с длиной диффузии как $1 / \mathrm{L}_{\mathrm{d}}{ }^{2}$. Реализация такой зависимости следует также и из разработанной нами грубой одномерной аналитической модели. Если площадь $p-n$-перехода мала, то площадь сбора фотоносителей уменьшается, что приводит к потере части сигнала в первую очередь отрицательной полуволны; кривая ЧКХ при этом сдвигается вверх, - и нуль ЧКХ может исчезнуть. С ростом толщины слоя абсорбера значение ЧКХ на частоте $2 \mathrm{f}_{\mathrm{N}}$ уменьшается.

Вместе с рассмотренным выше вкладом от фотогенерации электронов в p-области абсорбера, заметный вклад в формирование фотосигнала пикселя может давать также и фотогенерация носителей заряда в $n$-области $p$-n-перехода (несмотря на малый объём этой области и поглощение света в $p$ абсорбере). С уменьшением площади сбора носителей в р-области ЧКХ( $\left(2 \mathrm{f}_{\mathrm{N}}\right)$ изменяется в сторону более положительных значений, при уменьшении сбора фотоносителей в n-области ЧКХ -становится более отрицательной.

Рис. 1. Распределение фотоносителей в матрице на удвоенной частоте Найквиста. Волна засветки направлена по горизонтали. Знаками + и - обозначены фотоносители в р-области (электроны) для положительной и отрицательной полуволн засветки.

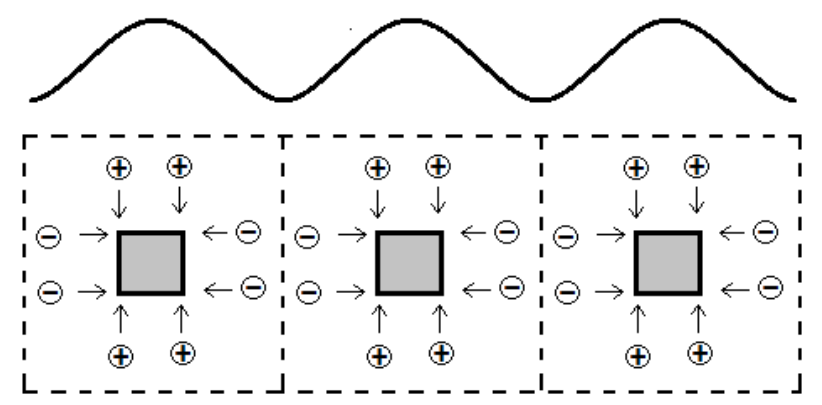

